\title{
TESTING PROCEDURES AND RESULTS OF THE PROTOTYPE FUNDAMENTAL POWER COUPLER FOR THE SPALLATION NEUTRON SOURCE*\#
}

\author{
M. Stirbet ${ }^{\dagger}$, I. E. Campisi, E. F. Daly, G. K. Davis, M. Drury, P. Kneisel, G. Myneni, T. Powers, \\ W. J. Schneider, K. M. Wilson, TJNAF, Newport News, VA 23606, USA \\ Y. Kang, Spallation Neutron Source, Oak Ridge, TN 37830, USA \\ K. A. Cummings, T. Hardek, LANL, Los Alamos, NM 87545, USA
}

\begin{abstract}
High-power RF testing with peak power in excess of $500 \mathrm{~kW}$ has been performed on prototype Fundamental Power Couplers (FPC) for the Spallation Neutron Source superconducting (SNS) cavities. The testing followed the development of procedures for cleaning, assembling and preparing the FPC for installation in the test stand. The qualification of the couplers has occurred for the time being only in a limited set of conditions (travelling wave, $20 \mathrm{pps}$ ) as the available RF system and control instrumentation are under improvement.
\end{abstract}

\section{INTRODUCTION}

The fundamental power coupler for the SNS superconducting cavities must be able to transfer up to $550 \mathrm{~kW}$ peak power over $1.3 \mathrm{~ms}$ pulse width at a repetition rate of 60 pps during machine operation [1].

Two prototype couplers have been manufactured and preliminary testing has occurred at Los Alamos National Laboratory (LANL) using a test stand specifically developed for this purpose [4]. The testing was done using a LANL 2.5 MW, 805 MHz RF source, with vacuum, arc, infrared interlocks and electron current monitors provided for window protection [2].

In this paper we present the methods used in assembling the FPC in preparation for testing and the results of the initial series of tests.

\section{ASSEMBLY PROCEDURES AND EXPERIENCE}

\subsection{General Layout of the FPC for SNS}

The FPC consists of a tapered $50-\Omega$ coaxial line with a planar ceramic window [2]. On the vacuum side of the assembly, the outer conductor is double-walled, heliumcooled, copper-plated stainless steel, and the inner conductor is OFE copper. The coaxial alumina window assembly has four instrumentation ports on the vacuum side: one for a vacuum gauge, one for an electron pick-up antenna and two sapphire optical view ports for infrared

\footnotetext{
* Supported by US DOE Contract No. DE-AC05-00OR22725

\# Los Alamos Report No. LA-UR 01-3156

†stirbet@jlab.org
}

and arc detectors. On the air side, the outer extension is made from copper-plated stainless steel and the watercooled inner extension is made of OFE copper. The FPC is matched to a rectangular WR975 waveguide via a doorknob/waveguide coaxial transition.

Modified Conflat ${ }^{\circledR}$ gaskets are used on the vacuum side of the window to provide good RF contact and, at the same time an ultra high vacuum joint [4]. To insure FPCs safe operation after RF conditioning [5], a capacitor for $\mathrm{DC}$ bias is provided.

\subsection{Incoming Inspection}

All components have undergone incoming inspections, including a check of dimensions on a coordinatemeasuring machine, a visual examination of the surface finish and vacuum leak checks.

Occasional marks and stains on the vacuum side of the window assemblies were observed. Also, the copperplating adherence to the stainless steel outer conductor jacket was checked by high-pressure water rinsing at 100 Bar for about 30 minutes.

\subsection{Components Cleaning and Clean Room Assembly}

Before assembly in a Class 100 clean room, the components were carefully cleaned. The outer conductors and all the stainless steel components (bellows, vacuum manifolds, connecting waveguide) were cleaned by a 15 minute immersion in an ultrasonic bath filled with a $10 \%$ solution of Micro-clean ${ }^{\circledR}$ detergent, followed by rinsing with de-ionized (DI) water and drying with dust free nitrogen gas. The window assemblies were also cleaned for 15 minutes in a DI water-filled ultrasonic bath before being transferred to the clean room where, additional cleaning with DI water jets was performed to reduce concentration of dust particles and contaminants trapped in the windows' RF chokes. Dust-free nitrogen was used to dry the window assembly after cleaning.

\subsection{Mechanical Assembly and Vacuum Tests}

The window assemblies were inserted into the preassembled outer conductors and connecting waveguide in the clean room. In addition the instrumentation ports were equipped with: a Balzers vacuum gauge, an electron pick 
up antenna and two sapphires optical view ports for IR and arc detectors.

The assembled connecting waveguide with the two couplers was transferred to the test cart and connected to the vacuum system. Vacuum leak test was performed with the test stand RGA [4] and additional integral leak checks were performed on each coupler using helium-filled plastic bags. Helium leak detection sensitivity of the system was better than $2 \times 10^{-10}$ Torr $1 / \mathrm{s}$.

\subsection{Baking}

The FPC couplers and the waveguide were baked out at $200^{\circ} \mathrm{C}$ for 24 hours for removing the adsorbed water [4]. RGA spectra were continuously recorded during baking.

No additional baking was performed after the original Conflat $^{\circledR}$ seals were replaced with modified ones, which insure good RF contacts.

\subsection{Electrical and RF Power Measurements}

The couplers' extensions were assembled after baking. A reinforcement bolting ring was used on the waveguide transition, which slightly modified the reflection coefficient. The biasing capacitor (insulated by a twolayer Kapton ${ }^{\circledR}$ foil, each with a thickness of $0.12 \mathrm{~mm}$ ) was inserted between the inner conductor extension and the doorknob and its DC and RF integrity was verified.

\section{TESTING APPARATUS}

An RF system consisting of a $805 \mathrm{MHz} 2.5 \mathrm{MW}$ pulsed klystron connected via WR975 waveguide to a watercooled high-power load was used to transfer the RF power through the FPCs as shown in Figure 1. Three sets of directional couplers (two between the klystron and the test cart and one between the test cart and the terminating load) were used to independently control the transmitted RF power levels. Additionally, the transmitted power was measured calorimetrically at the load [6].

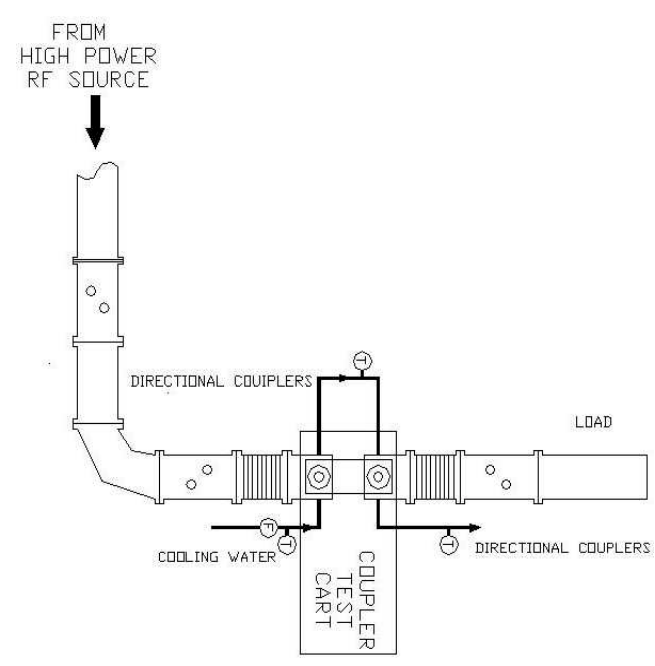

Figure 1: RF layout used in testing SNS couplers.

\section{TEST RESULTS}

\subsection{Initial Results}

RF conditioning at high power was performed at LANL. Starting with pulse duration of $1 \mathrm{~ms}$ at $1 \mathrm{pps}$ repetition rate, over $100 \mathrm{~kW}$ peak power was reached without any vacuum activity. A vacuum outburst occurred at about $125 \mathrm{~kW}$. After vacuum recovery the normal conditioning process (with vacuum and electron activity) was restarted from $35 \mathrm{~kW}$. In less than 24 hours of RF conditioning with different pulse durations and repetition rates (from $100 \mu \mathrm{s}$ to $1 \mathrm{~ms}$ and at 1,10 and $20 \mathrm{pps}$ ), $500 \mathrm{~kW}$ peak power was reached (Figure 2).

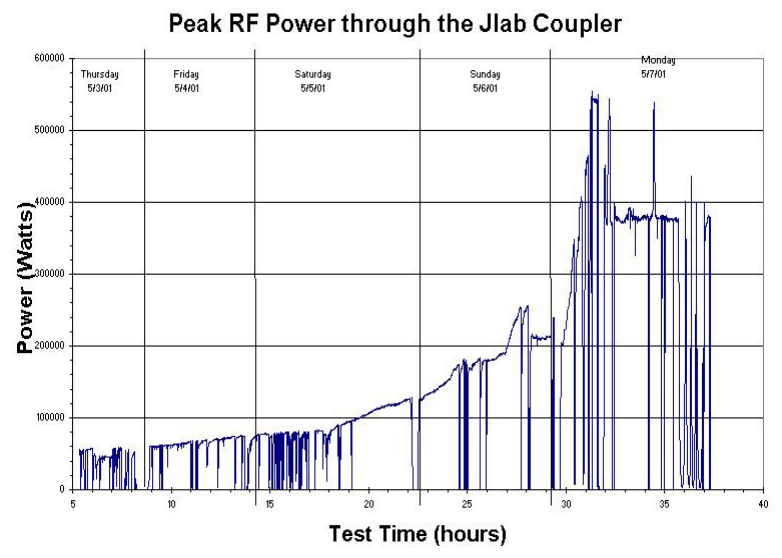

Figure 2: RF conditioning and power tests as recorded on an independent power meter at LANL.

The amplitude of the klystron drive was maintained for different period of times at various levels and at $500 \mathrm{~kW}$ for more than 30 minutes (Figure 3). During those tests the vacuum was better than $10^{-8} \mathrm{mbar}$, and the electron activity in the picoAmpere range.

Even if arcing events on the air side of one of the couplers occurred at $300 \mathrm{~kW}$, tests at $350 \mathrm{~kW}$ were continued for several hours, without being affected by vacuum or electron activity.

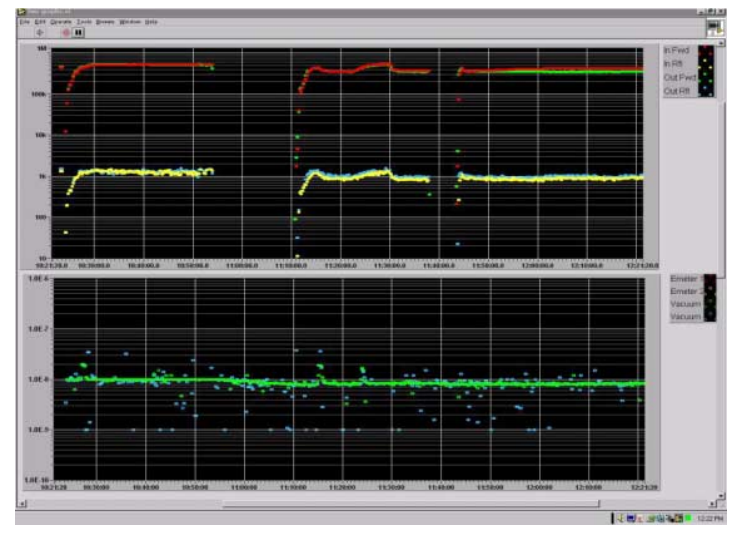

Figure 3: $500 \mathrm{~kW}$ of RF on the FPC. Vacuum levels on both couplers were better than $10^{-8}$ mbar. 
After RF conditioning, no evidence was observed of multipacting up to $550 \mathrm{~kW}$. Also, no appreciable temperature increase was observed during RF processing.

\subsection{Reconditioning}

The test cart and the SNS FPCs were kept under vacuum for a period of two weeks and then exposed again to RF (pulse duration $1 \mathrm{~ms}$ and repetition rate $20 \mathrm{pps}$ ).

Less than two hours RF reconditioning was necessary before reaching $300 \mathrm{~kW}$.

Vacuum and electron activity and some non vacuumrelated arcing events were recorded by photomultiplier tubes only on the vacuum side of the output coupler (Figure 4).

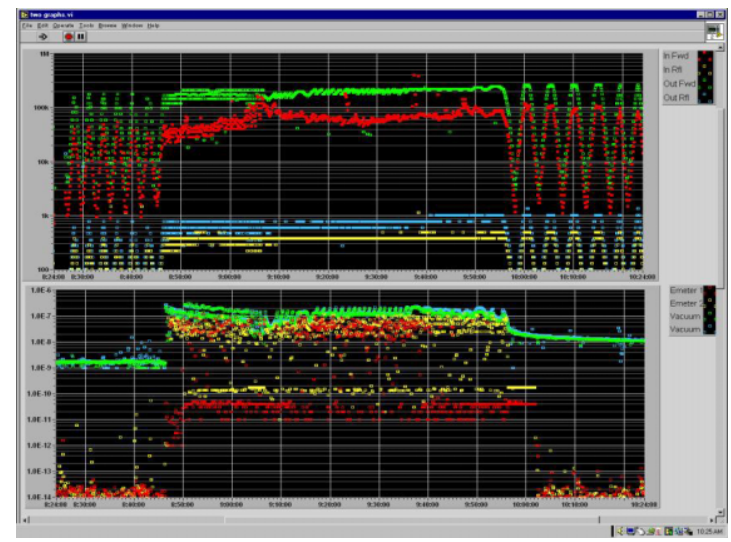

Figure 4: Less than two hours conditioning with controlled vacuum at about $3 \times 10^{-7}$ mbar were needed after two weeks of RF off.

During this RF conditioning hydrogen was noted to be the dominant desorbing gas specie (Figure 5).

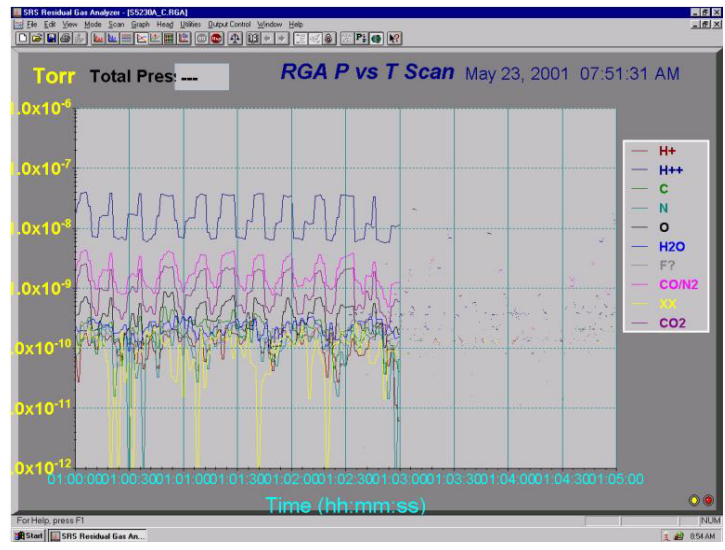

Figure 5: Partial pressure of residual gas species during $\mathrm{RF}$ conditioning at $160-180 \mathrm{~kW}$.

After reconditioning, (Figure 6) no more spurious arcing or vacuum events were observed and the RF power could be cycled and maintained constant at $300 \mathrm{~kW}$, then cycled again and increased to over $550 \mathrm{~kW}$.

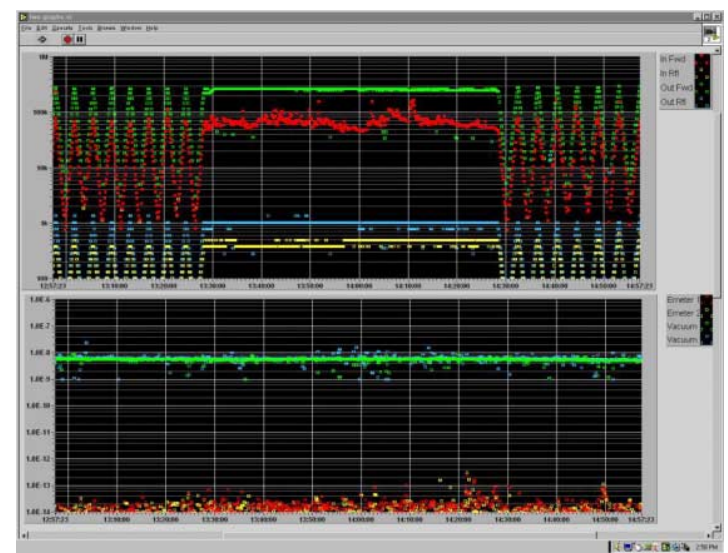

Figure 6: Power test up to $300 \mathrm{~kW}$ after RF conditioning, showing no more vacuum or electron activity.

\section{CONCLUSIONS}

A series of tests were performed on the prototype SNS fundamental power couplers. Peak power levels in excess of $500 \mathrm{~kW}$ were achieved without strong evidence of multipacting problems or average heating problems. The work will continue to extend the tests to full $1 \mathrm{MW}$ standing wave power at $60 \mathrm{pps}$ as soon as the RF power source will be ready for this mode of operation.

\section{ACKNOWLEDGEMENTS}

The authors wish to thank R. Afanador, J. Brawley, R. Bundy, B. Carpenter, S. Castagnola, I. Daniels, C.Grenoble, T. Elliott, L. King, P. Mutton and W. Sommer at JLAB, P. Torrez, R.Przeklasa, D.K. Warner, J.S. Harrison and D. Pippin at LANL for the essential assistance in the activities leading to the testing the first SNS prototypes FPCs at LANL.

\section{REFERENCES}

[1] http://www.sns.gov/documentation/100000000PL0001-R05.pdf - SNS Parameter List

[2] I. E. Campisi et al., "The Fundamental Power Coupler Prototype for the Spallation Neutron Source (SNS) Superconducting Cavities," PAC2001, Chicago, IL, June 2001.

[3] Y. Kang et al., "Electromagnetic Simulations and Properties of the Fundamental Power Couplers for the SNS Superconducting Cavities," PAC2001, Chicago, IL, June 2001.

[4] M. Stirbet et al., "Processing Test Stand for the Fundamental Power Couplers of the Spallation Neutron Source (SNS) Superconducting Cavities," PAC2001, Chicago, IL, June 2001.

[5] J. Tuckmantel et al, "Improvements to Power Couplers for the LEP2 Superconducting Cavities", in Proc. of the PAC'95, Dallas TX, May 1995.

[6] K.A. Cummings et al., "Results and Lessons Learned from Conditioning $1 \mathrm{MW}$ CW $350 \mathrm{MHz}$ Coaxial Vacuum Windows", Linac98, Chicago, IL, August 1998. 